Original Research Paper

\title{
Effects of Environmental Change on Human Health: A Descriptive Economic Analysis
}

\author{
${ }^{1}$ Uttam Paudel, ${ }^{2}$ Shiva Raj Adhikari and ${ }^{3}$ Krishna Prasad Pant \\ ${ }^{I}$ Environmental Health Economist, Tribhuvan University, Nepal \\ ${ }^{2}$ Health Economist, Tribhuvan University, Nepal \\ ${ }^{3}$ Environmental Economist, Kathmandu University, Kathmandu, Nepal
}

Article history

Received: 18-05-2018

Revised: 07-12-2018

Accepted: 5-01-2019

Corresponding Author:

Uttam Paudel

Kathmandu-3, Bairochan Marg,

37/7, Kathmandu, Nepal

Email: uuupaude122@gmail.com, uttampd112@gmail.com

\begin{abstract}
Environmental dilapidation in developing countries upsurges the incidence of human diseases leading to societal impoverishment in the disease rampant areas. Literatures on economic evaluation of effects of environmental changes on human health are scanty. This paper descriptively reconnoiters major environmental changes, spread of diseases, associated household cost including health costs and finally benefits from the improvement of environment through household survey in western Nepal. The results ratify that draught, thunderstorm, lightning, flood and heat waves stand as the major climate-induced natural disasters affecting human health where people directly rely on agriculture for livelihood and firewood for cooking in western Nepal. Increasing temperature and decreasing rainfall in all seasons are found parallel with the increasing incidence mostly of waterborne and foodborne diseases in the hilly region and vector-borne diseases in Terai region. Increasing disease incidences with new diseases under the changing environment have aggravated an average of NPR 61,539 (NPR $104=$ US\$ 1) as direct household curative cost and reduced working efficiency of the patients by $47 \%$ at least for a year. Direct adaptation cost in household level is estimated as almost NPR 81,500 which is catastrophic among the remittance-dependent poor community. With poor coverage of life insurance but highly excited towards health insurance in the community, people seem willing to pay more than the government existing rate (NPR 2,500) for ensuring sustainable health security. Finally, the household's benefit from the improvement of environmental quality partially causing the diseases incidence elicited by the willingness to pay method is obtained as NPR 1,909 per year on an average. From the policy perspective, the results can be destiny in the formulation of environmental conservation plan and generation of self-motivation to the people around disease prone areas in western Nepal.
\end{abstract}

Keywords: Adaptation Cost, Environmental Changes, Human Health, Health Cost, Nepal

\section{Introduction}

In broad-spectrum, environmental vicissitudes including environmental degradations and climate change ultimately causing economic losses to the people with technological backwardness in developing countries are partially or wholly responsible for decreased productivity and increased health problems. Within these problematic burning issues, scientists are still working for developing evidences through integrating assessment methods. Environmental threats to the health of children in South Asia and the Western Pacific are myriad and include hazards of classic infectious diseases like pneumonia, dengue, malaria, dysentery, measles, AIDS and tuberculosis (Bonjour et al., 2013; Zuckerman, 2012). However, most of the studies innocuously using data from household surveys to analyze the health impacts of environmental conditions are found with four problems: biased estimate, improper sample size, sample selection bias and errors in measuring environmental conditions (Paudel, 2018a).

Environmental hazards influence or are even responsible for about one-fourth of the total burden of diseases worldwide, mainly communicable diseases in 
developing countries and non-communicable diseases in developed countries (WHO, 2017). An unexpected sporadic emergence of infectious diseases in the tropical region is attributed to biological, environmental and social factors (Young et al., 2017). The disease burden can be influenced often by the result of diverse environmental, social and behavioral risk factors (PrüssUstün et al., 2016). Human behavioral factors create a force for the destruction of the environment quality especially, such as urban development and traffic resulting in the effects on human health.

Releases of untreated volume of general and toxic wastes with upsurge in the global population are serious health hazards which result in the blowout of infectious diseases (Alam and Ahmade, 2013). Sustainable development goal-13 proposes to minimize the adverse effect of environmental degradations - specifically climate change on human health, all the countries must achieve the environmentally sound management of chemicals and all the waste (WHO, 2016). Changes in climate are always occurring because of natural factors which is referred as climate variability and a humaninduced component as climate change (Chan et al., 1999). Climate change causes ecosystem alterations increasing potentials of outbreaks of vector-borne diseases (Liang and Gong, 2017). Persistence or reemergence of non-infectious and infectious diseases may also be indicative of wider problems affecting the dynamics of socio-ecological systems, environmental and climate changes, changes in host ecology and selection pressures from insecticides (Sattenspiel, 2000; Tol, 2009).

Environmental degradations negatively affect most biological systems, a direct concern of the well-being and survival of many species in the planet (MOHP, 2011; Tjaden et al., 2017). More specifically, at an organism level, the effects lead not only to endocrine disruptions, sex-ratio changes and decreased reproductive parameters but also include teratogenic and genotoxic effects, immune-suppression and other immune-system impairments, abnormal cell replication and deleterious mutations (Acevedo-Whitehouse and Duffus, 2009). A fact that almost $40 \%$ population of developing countries and about $2 \%$ of the developed world are commonly infected with at least one infectious or parasitic diseases in lifetime due to the differences in socioeconomic conditions, including nutrition, sanitation, housing, working conditions and availability of health care (World Resources Institute, 2003).

Environmental changes and their health effects indicate a great deal of heterogeneity due to the differences in study design, but climatic and socioeconomic differences that vary by location also influence the burden of diseases. Therefore, development of a comprehensive catalog of environmental changes and associated health outcomes evidences across the range of environment and populations at risk can frame an understanding with motivations in the control of effects of environmental change in a particular region. Countries like Nepal, India have tremendous opportunities to guide future trajectory regarding sustainable development and adaptation to climate change, but it will take the combined effort of policymakers and scientists from around the world to address the complex challenges associated with overall environmental change and human health. In addition, a broad assessment of climatological and ecological changes determining disease emergence and redistribution can ultimately help to target dynamic preventive strategies, for example, to reduce the impact of extreme weather episodes and pollution on human health.

Many evidences are accessible focusing only on the general concern of climate change and its effects at the time of brutal debacle posed by nature rather than the cost valuation of the effects of environmental change on human health. The cost of diseases may be mammoth in the future as explained in a paper (Paudel, 2018b) based in Nepal. Direct and indirect cost burden of the diseases to the individual/society due to the climate change can be considered a cause of impoverishment to those directly exposing in environmental degradation from different activities. If this concealed future daring information relics overlooked at this time, the economic consequences of effects of climate change on disease will be gargantuan due to its downbeat externalities. With the inclusion of economic cost and benefit, a descriptive analysis of effects of environmental change on the diseases, a concern of not addressed by any literature till the date in Nepal (Paudel, 2018a), is found timely and apposite research at this moment as a tool for motivating towards health consequences and environmental protection through an economic perspective. This paper mainly aims to investigate descriptively the impact of environmental change on the household economy of Nepal.

\section{Research Methods}

\section{Research Design}

Cross-sectional descriptive economic evaluation design is employed using both primary and secondary data. Based on the objective of the study, primary data are foremost for results which are collected from two study areas of western Nepal and secondary data were supplementary for obtaining the results as collected from published resources for the investigation of environmental effects on human health descriptively, maintaining both qualitative and quantitative aspects. After obtaining sampling frame from a pilot survey, simple random sampling method was employed to collect the data. A total of 420 households were selected for survey in this study. Record reviews, focus group discussion, in-depth interviews with health professionals and community people were the fundamental techniques for data collection with a structured questionnaire containing both qualitative and quantitative aspects. 


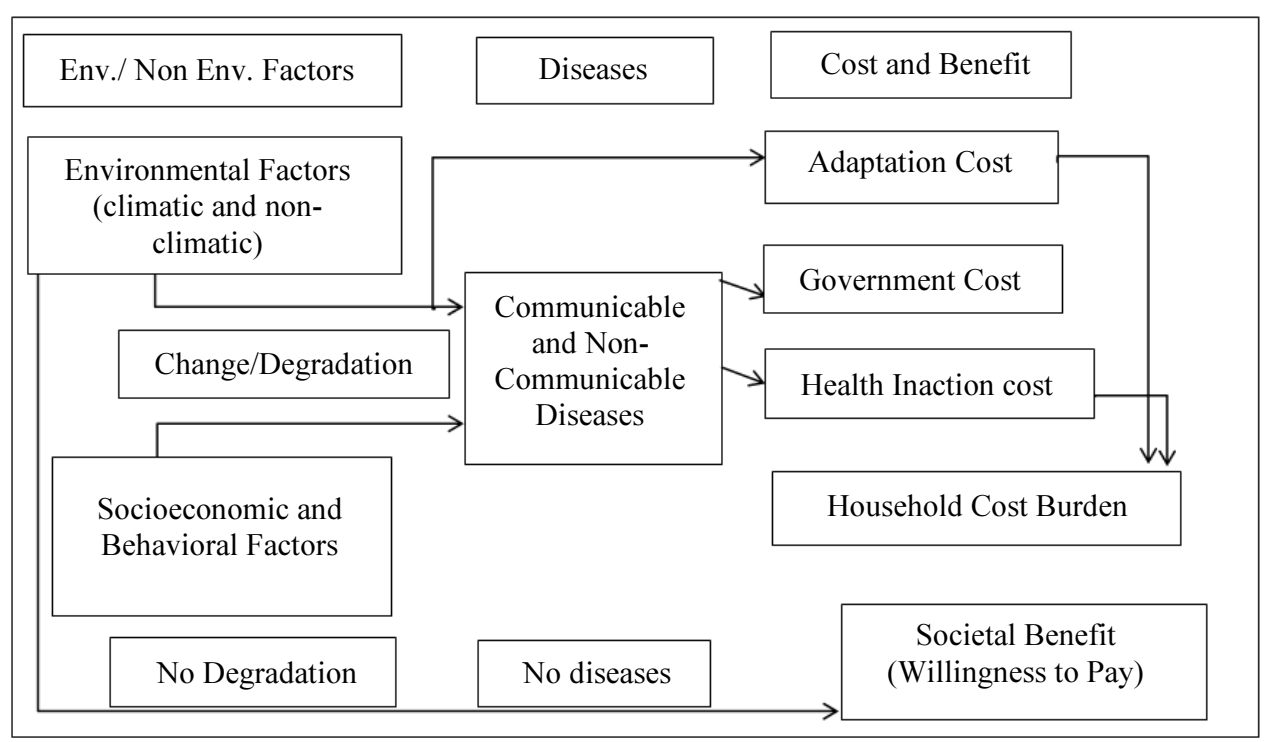

Fig. 1: Conceptual framework

Collected data were entered into the SPSS for the analysis. In order to estimate cost and consequences through societal perspective, household cost and consequences were estimated with field survey data both qualitative and quantitative as summarized in conceptual framework in Fig. 1.

\section{Description of the Study Areas}

Based on the high sensitivity with environmental change and high level of incidence and prevalence of diseases as identified from past evidences (Paudel and Pant, 2018), experts suggestions and annual reports of health and environment ministries, two most diseased districts of western Nepal, Jajarkot and Banke that join higher mountain to terai region, were chosen for the household survey. These areas are located between N28 $37^{\prime} 22^{\prime \prime}$ to $29^{\circ} 07^{\prime} 32^{\prime \prime}$ and E81 ${ }^{\circ} 49^{\prime} 22^{\prime \prime}$ and 82 $34^{\prime} 46^{\prime \prime}$. Western Nepal is well known as the highest diseased area of Nepal.

The altitudes of Jajarkot district vary from $5440 \mathrm{~m}$ altitude to $610 \mathrm{~m}$ within the district. A poor socioeconomic status, high mountains and transportation difficulties and less availability of river distribution across the district inform the complexity of the local life. Out-migration of youth mostly to India for search of job for their annual family survival is common. Lack of proper transportation facility many often cause people to lose their life attributing to treatment paucity against the continuous and sudden outbreak of diseases every year.

Banke district is in plain Terai region having 109 to $1950 \mathrm{~m}$ altitude. The socioeconomic status of Banke is quite accessible for the health and education services because of transportation and other electricity access. The climate of the districts ranges from tropical to subtropical. The regular incidence and high prevalence of diseases within these regions of Nepal, one of the climate-sensitive areas, seem rampant but still unknown for concrete reasons. Therefore, these areas are the potentially informative areas for this study aiming to identify the determinants of diseases incidence and environment-health relationship as well.

\section{Study Setting and Designing}

Prior to the final household survey, a rapid assessment study and pre-test within the study areas were carried out to check the suitability of questions for the selected samples and validity of household survey questionnaire perfectly balancing the flow of questions. The questionnaire incorporates environmental, socioeconomic and household behavioral related quires including the cost incurred by the household for the treatment of patient for the particular disease as well as the task for adaptation of effect of environmental change. After the completion of semi-structured questionnaire finalized with the aid of expert suggestions, a pretest was conducted among 20 rural households at the high-risk area of Kavre district, leading to final questionnaire check for flow of questions.

Enumerators, public health graduates, were then selected for the data collection from the targeted fields. District Public Health Office in Jajarkot suggested Veri municipality, around $40 \mathrm{~km}$ away from district headquarter, as one of the most disease-prone areas for the survey. In this municipality, the most affected villages are Fera, Karkigaun, Rattigan, Jagadipur and Mahatara Gaun where most of the residents are Dalits and Chhetri. Similarly, Nepaljung municipality and Janaki village municipality in Banke district were selected for the study based on the records of District Public Health Office in the district. 


\section{Sampling Technique, Sample Size and Data} Collection Method

With the sampling frame containing a detail list of households obtained from the office of municipalities during rapid assessment survey, samples were selected within the criteria that at least 75 households from 3 wards were chosen by simple random sampling method considering about $500 \mathrm{~m}$ distance from one sample to another. Three wards were selected from each municipality locating in urban, semi-urban (one kilometer away from main market and main road) and rural. This gives a total of 420 households sample size for this study. This study by nature seeks the disease incidence due to environmental indicators changed over last 15 years.

The key informants were health professionals and community people with age above 35 years. The survey was steered from March 18 to March 28, 2018 with indepth interviews among the subjects. Two focus group discussions were conducted among local leaders, community people and health professionals. Field supervisor checked all the information riched questionnaires on the same day in the field to detect cases of missing and incomplete information or irrelevant responses. Researcher frequently visited the field during the time of data collection. To make the data more precise, researcher's supervisor also sometimes checked the data collected through sharing of data in email. Collected data were entered into SPSS and transformed into STATA for the analysis.

\section{Estimation of Health Inaction Cost and Adaptation Cost}

Cost simply refers inputs to fulfill the expectation of better health output. The costs incurred by the household for the treatment of diseases and adaptation activities were calculated using the ingredients approach through reviews of published and unpublished literature, direct interviews and focus group discussion.

Direct cost: Direct cost of treatment of diseases includes both curative and preventive costs incurred by the household from their out of pocket. The direct cost of household is calculated from ingredient approach. Direct curative cost again includes transportation cost, medicine cost, food and water, equipment rent and registration fees. Direct preventive cost includes the out of pocket payment of household made for the preventing activities for the protection of family from disease occurrence at home.

Indirect cost: It includes time loss of patients and caregivers for the recovery of illness. Both the curative and preventive household time losses are presented in the result section. Besides, adaptation cost includes house repairing cost, cost for electronic devises and clothes etc.

\section{Household Benefit (Willingness to Pay)}

The societal benefit is obtained with the willingness to pay method. A hypothetical situation was created explaining a scenario given below and asked a question for their response (benefit):

\begin{abstract}
........the incidence and intensity of different diseases along with climate and environmental disaster that you have been facing ...... a hypothetical situation where you are safe from all these climate caused diseases. ... the better situation of some environmental components such as safe water management, air quality assurance; so that your locality will have least chance of diseases incidence and prevalence... reduction of disease incidence, improve the individual/household/community behavior through above-mentioned intervention. Therefore, you are required to pay one time out of pocket payment within this year.

Question: How much the maximum are you willing to pay for the intervention at once if your payment completely protects you from any diseases caused by environmental degradations and natural disaster afflicting your locality? NPR ....
\end{abstract}

\section{Hypothesized Variables}

The study aims to explore the effect of environment on health through the use of cross-sectional analytical design. For this, research incorporates variables which are recently daring the local specific area representing national issues. Therefore, the variables in the use of finding a descriptive association between environment and disease (but association not included in this paper) are given as follows:

- Dependent Variable: Disease prevalence

- Independent Variables: Environmental determinants, household based socioeconomic variables and household behavioral indicators

The environmental variables include, knowledge and perception about environmental change, natural disasters due to environmental change (draught, fire in forest, flood, windstorm, thunderstorm, heavy rain, sporadic rain, landslide, snowstorm, erosion, heat waves and cold waves); changes in water resources (amount of water, quality, level, dry up of spout and flow in piped water); household socioeconomic and behavioral indicators (sex, age, education, marital status, income, current occupation, ownership of residence, source of drinking water, main source of energy for cooking and lighting, main types of toilets, hand washing habit, disposal of waste and food preferences). 


\section{Results}

\section{General Information of Household}

Regarding the basic characteristics of households in a descriptive manner, of the total 420 respondents, $56 \%$ were male distributing into four ethnicities, namely Brahmin/Chhetri (24\%), Janajati (5\%), Dalits (24\%) and others $(3 \%)$. Almost equal number of Dalit males and females participated in the study as shown in Fig. 2. Compared to the males, less number of Brahmin and Janajati females are available for the response. Other includes Muslims and other castes.

Regarding the age of the household head ( $\mathrm{HH}$ head) in the study, the mean age of the $\mathrm{HH}$ head is 44.72 years with very small standard deviation, covering least age of 35 up to 80 among the respondents. The average family size of the respondents is found 6.5 which is quite higher than the national figure (4.88) according to the 2011 census survey of Nepal. Comparison between two study sites displays that the family size in the southern part is higher than that in comparison to the northern part. For the case of education of $\mathrm{HH}$ head, the average education level is only 3.4 years of schooling because of the significant number of respondents in Jajarkot were illiterate because of distant high school and high dropout rate.

Almost $96 \%$ of respondents were married because of age requirement of the respondents who was HH head too. Most of the elderly people are illiterate or limited within primary education (see in Table 1), while very less (12 respondents) people are with higher education. Only one respondent was available with higher education in the northern part. Comparatively, educational status is higher at southern part compared to the northern part. Agriculture is the dominant occupation among them as illustrated in Fig. 3. Service and business are other major occupations for few households but are supplementary for the income generation.

Interestingly, $98.8 \%$ of the sample households reside in their own houses, with $53 \%$ houses are semipermanent and $21 \%$ permanent. And less than $1 \%$ household heads are in the rent, especially the professional for service or business. Moreover, $18.3 \%$ households live in their own semi-permanent house. The main source of drinking water is different based on the locations. In the southern study area, spring well is the major source of drinking water for $52 \%$ of households whereas piped and river water are in northern part of study areas. Dhungedhara (water spout) is also a supplementary source of drinking water for the study areas.

Only wood and LPG gas are the main cooking fuels covering $78 \%$ and $22 \%$ of total households, respectively. Wood and LPG are supplementary to each other for the entire cooking foods at home. Regarding lighting sources, electricity covers $88 \%$ of households in Terai region and use of solar seems popular in hilly study area because there is no electrification, 3\% of households belonging to the hilly area reported nothing for lighting.

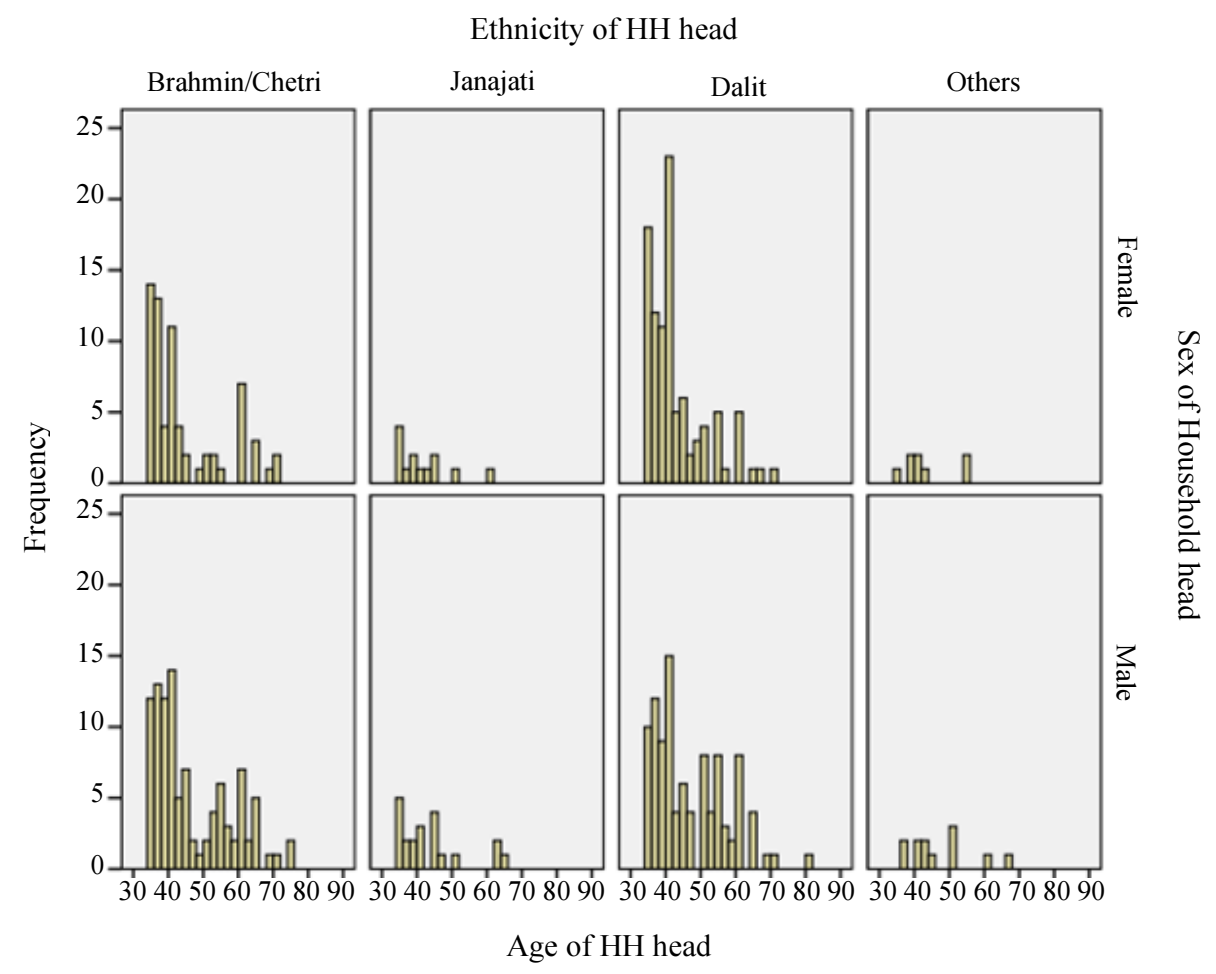

Fig. 2: Age of HH Head by Sex and Ethnicity 


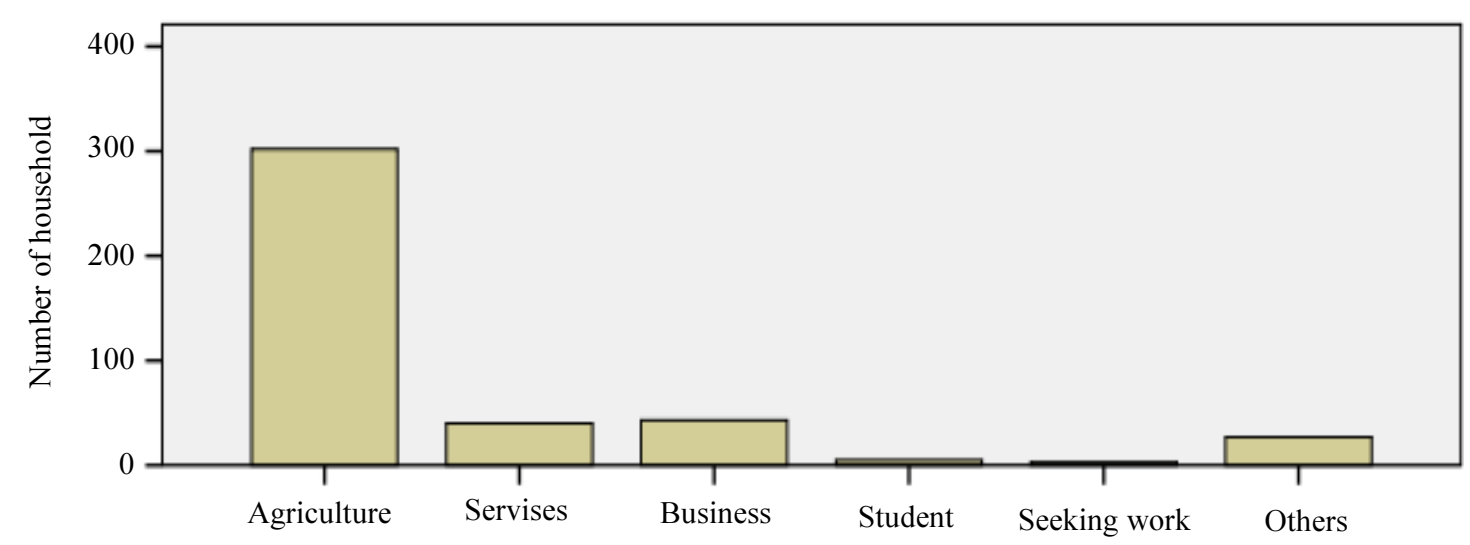

Fig. 3: Occupation of household head

Table 1: Education level of the household head by marital status

Education category

\begin{tabular}{|c|c|c|c|c|c|c|c|}
\hline & & Primary & Lower Secondary & Secondary & Higher & Illiterate & Total \\
\hline \multirow{3}{*}{ Marital Status } & Married & 72 & 44 & 62 & 12 & 214 & 404 \\
\hline & Unmarried & 2 & 0 & 2 & 0 & 3 & 7 \\
\hline & Widowed & 2 & 0 & 1 & 0 & 6 & 9 \\
\hline Total & & 76 & 44 & 65 & 12 & 223 & 420 \\
\hline
\end{tabular}

Table 2: Household's income sources (NPR)

\begin{tabular}{lllll}
\hline & $\begin{array}{l}\text { Income from } \\
\text { Agriculture }\end{array}$ & $\begin{array}{l}\text { Income from } \\
\text { agriculture and forest }\end{array}$ & $\begin{array}{l}\text { Income from } \\
\text { livestock }\end{array}$ & $\begin{array}{l}\text { Income from business } \\
\text { and others }\end{array}$ \\
\hline Mean & 44,225 & 117,283 & 28,344 & 214,554 \\
Minimum & 1,000 & 5,000 & 1,000 & 2,000 \\
Maximum & 450,000 & 360,000 & 372,000 & $4,024,000$ \\
Standard Deviation & 57,021 & 44,485 & 74,536 & 289,196 \\
\hline
\end{tabular}

Agriculture seems testimony for income generation at home as shown in Table 2. Almost $63 \%$ of the total households are reliant on agriculture. Remittance poses second major income source that covers $15 \%$ of total households. Few households are also dependent on social security allowance as their major source of income. Agriculture and wages are the major sources of income for the case of hilly areas. Remittance basically from India is also the next potential source of income in the hilly region. While in the Terai region, agriculture and business are major sources of income, which complement each other.

Because of improper drainage system in the study area, least number of households use flushed toilet connected to drainage, with the dominance of simple toilets as shown in Fig. 4. Basically, in Terai region, flush toilet connected to tank seemed common. Similarly, households with no toilet are mostly in hilly areas, basically the residents nearby to the riverside.

Of the total sample households, $29 \%$ of the household receives remittance. Remittance is basically from India for both the study areas. Remittance ranges from NPR 20,000 to 800,000 per annum. About $81 \%$ of the total households have their own land for cultivation, ranging from 0.05 ha to 16.00 ha with mean 1.00 ha $(\mathrm{CI}$ : $0.80-1.26$ ). Only a few of them have used their land for rent comparatively at a low price.

\section{Access to Socio-Economic Services}

Concerning to the socioeconomic services in the study areas, $76 \%$ of the households do not have any membership in microfinance or any other organizations. Though they have or not the membership in any organization, $50 \%$ of them are aware of small savings for the sake of hard times. Only $16 \%$ of households have membered in the community-based organizations (Women groups and others). Around $89 \%$ of the people in the study area are still deprived of having agricultural or veterinary services though their main occupation is agriculture. The average distance from home to the nearest motorway, health post and secondary school vary with high standard deviation shown in the Table 3. No single household use new agriculture system where agriculture is the major occupation in the study areas with a long experience more than 20 years. 


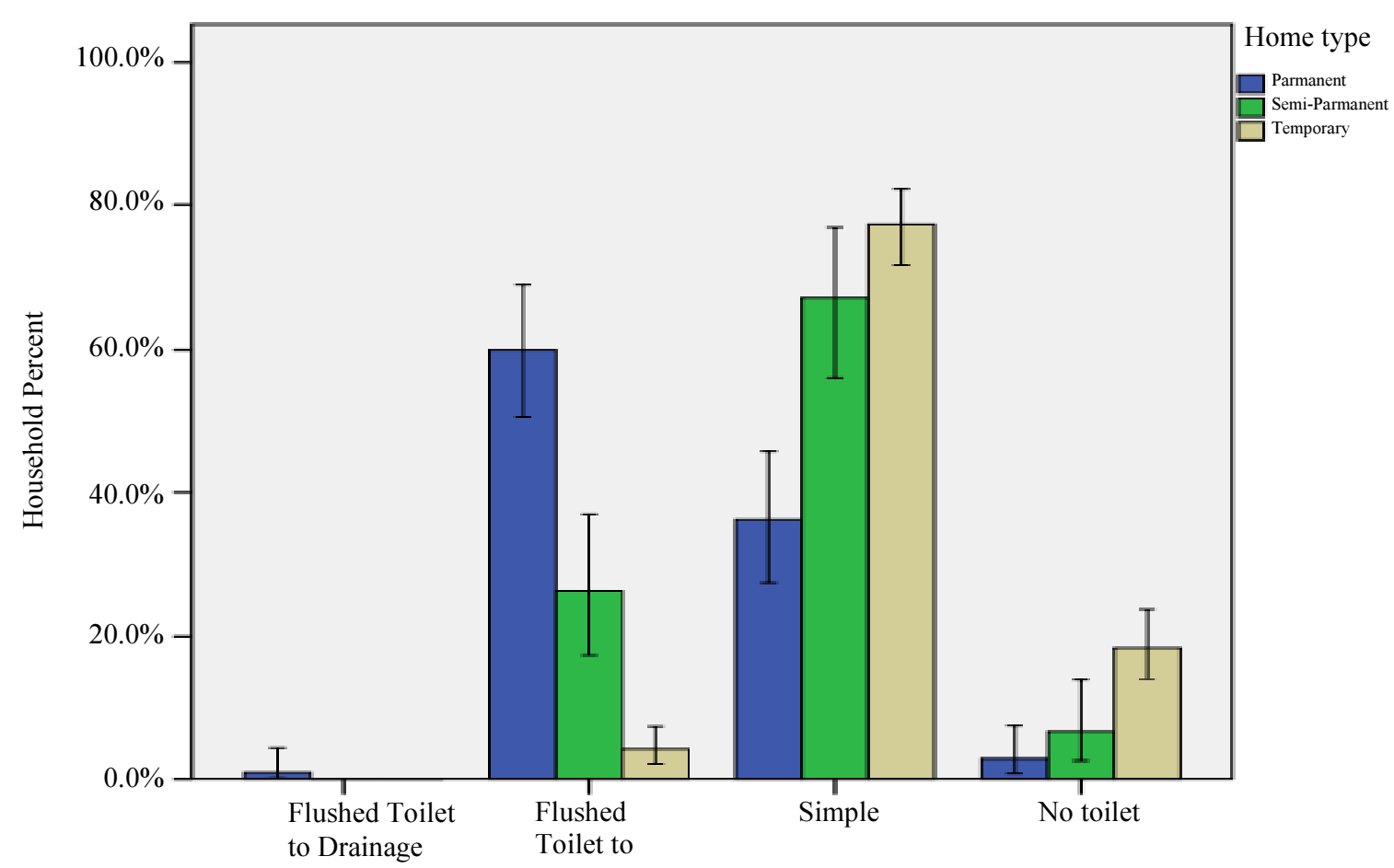

Fig. 4: Toilet types by home type

Table 3: Household's socioeconomic access

\begin{tabular}{lllll}
\hline Description & Minimum & Maximum & Mean & Std. Deviation \\
\hline Distance to the nearest motorway (KM) & 0.1 & 50 & 4.14 & 4.50 \\
Distance to the nearest health post (KM) & 2 & 16 & 2.77 & 1.98 \\
Distance to the nearest secondary school (KM) & 3 & 20 & 2.68 & 2.09 \\
\hline
\end{tabular}

Of the total households, only $13 \%$ of them have the membership in political or social organizations. Those who are member are also being used as either demonstration or passive members. Might be, for this reason, they feel their time to the organization only to spend the leisure time rather than any expectation of devotion to social change. Therefore, they have the least effect of being membership in these organizations without payment.

\section{Information on Temperature and Rainfall}

Temperature and rainfall are the major climatic indices. Based on the survey data, almost $91 \%$ of the households have now felt increasing temperature compared to some years ago as demonstrated in Fig. 5. Locals argued that temperature has been dramatically increasing in increasing order in hilly areas as, rather smoothness in Terai region. The temperature for both summer and winter have increased in the study areas and the frequency of monsoon and winter rain has reduced which might be a significant cause in diseases emergence due to the livable environment for agents spreading disease.

\section{Climate Knowledge and its Effects}

Interestingly, $49 \%$ of total households listened to climate change mainly through television in Terai region and awareness program in Jajarkot. Among those who listened to climate change, $97 \%$ responded for a changing climate. The major reasons for climate change as per them are mainly deforestation in Jajarkot and, natural reasons and overuse of resources in Terai regions.

Draught, the major effects of climate change as around $88 \%$ of households have felt of draught leading to low production of agricultural crops, is followed by flood, thunderstorm, heat waves, cold waves, diseases and landslide are the other potential effects of climate change in western Nepal. Of those effects which are highly active incidence of drought, flood, thunderstorm and diseases are increasing continuously because of low or heavy rain, deforestation, increased population and road construction. Thunderstorm, flood, landslide and diseases are the major causes to increase the loss of property in the study areas. Though a large number of people being affected directly or seen the effect to others, few people (mostly females) had lost their lives from the disasters. 


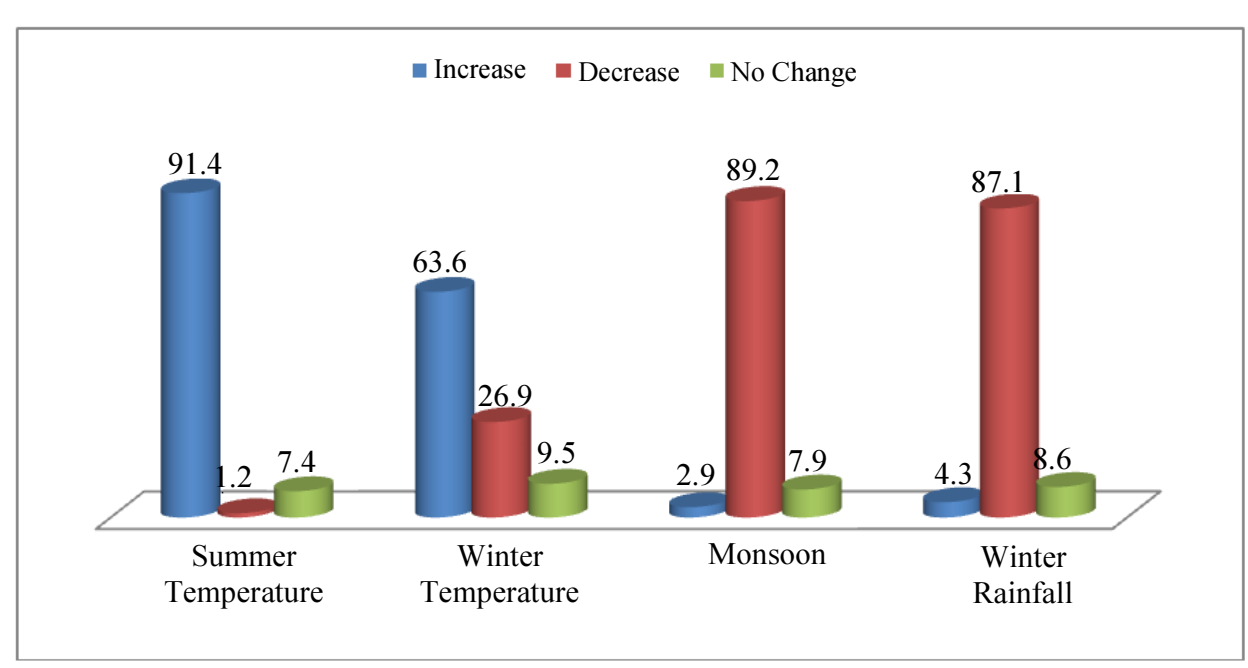

Fig. 5: Change in Temperature and Rainfall

\section{Disease Incidence and Prevalence under Environmental Change}

Undoubtedly, two third households have expressed an increasing trend of sickness in their families. Basically, diarrhea, asthma, pneumonia, typhoid, kidney stone, diabetes, cholera and gastritis are the major diseases increasing in the northern part of the study area, whereas heart diseases, malnutrition, uric acid, typhoid and asthma are rampant in the southern part of western Nepal.

Regarding new diseases in the study area; Filariasis, Appendicitis, Bird-flu, Swine-flu, heart diseases are the new spreading diseases in Terai region and diabetes, pneumonia, diarrhea, jaundice and stone are newly getting rampant in Jajarkot district of western Nepal. Malaria and Japanese Encephalitis are increasing all over the low land of western Nepal. Similarly, diarrhea, typhoid, jaundice and cholera are found increasing in the study areas. Joint aches, abdominal cramps, diarrhea and vomiting are common in the study areas regarding the water borne diseases.

\section{Direct and Indirect Cost of Healthcare in Household Level}

Of the total patients cured of different diseases, $71 \%$ were females. The average hospital visits of patients per households is 8 times with the range of zero to 61 times per year, incurring the average total cost as NPR 61,539 per household as demonstrated in Table 4. For the treatment, the average out of pocket payment of the household for medicine purchase is NPR 55,653 which can be supposed to be a major burden of diseases in the study areas.

Similarly, the average time spent on reaching the hospital is nearly 4 hours. The average hospitalized days are 16 per patient. Importantly, the restriction of working capacity of the patients after when once had sickness is around more than $47 \%$. The caregivers had also spent 5 days on average for the recovery of the diseases as presented in Table 5.

\section{Adaptation Cost at Household Level}

Households have paid for the protection of themselves from different unanticipated environmental hazards. The average payment for the net used in window and doors especially in Terai region is found as NPR 8,862 in the last 5 years. Similarly, the average direct preventive cost incurred by households for mosquito net, pesticide, skin care product and others are given in Table 6.

\section{Climatic Effect on Air and Water}

Unexpectedly, increasing pattern of movement of hot air in higher hilly areas of the study areas is responded by $64 \%$ of the respondents. It is normal to feel the hot air in lower Terai region but increasing intensity of hot air is reported from both hilly and Terai regions compared to 15 years ago.

Regarding water resources, the amount of water in the rivers, ponds and wells has been continuously decreasing for last 15 years. Moreover, water quality in these water resources found to be deteriorating day by day from human activities in the study areas. Decreasing water quality of the available water in the community might pose a serious threat of environmental change. In the hilly areas, deforestation and overuse of resources were attributed to the climate-induced disasters. Therefore, these reasons might be connected with decreasing water amount and quality in the river. Because of the lack of pond and wells in the hilly study area, most of the people are unknown about water and its quality in ponds and wells. However, it is directly applicable to terai region, where $88 \%$ of total samples of terai region responded a decreasing water quantity and its quality in the water sources they are using. 
Table 4: Direct curative cost of households

\begin{tabular}{lclll}
\hline Cost items in NPR & Minimum & Maximum & Mean & Standard deviation \\
\hline Transportation cost to health center & 50 & 135,000 & 4,816 & 10,767 \\
Medicine cost & 200 & 850,000 & 55,653 & 77,505 \\
Food and water & 100 & 50,000 & 4,909 & 6,988 \\
Rent for devices & 500 & 5,000 & 2,000 & 2,121 \\
Registration fee & 30 & 500 & 430 & 13 \\
The total cost of treatment & 100 & 986,000 & 61,539 & 83,660 \\
\hline
\end{tabular}

Table 5: Household time loss for the cure of patients

\begin{tabular}{|c|c|c|c|c|c|}
\hline Time loss Items & Range & Minimum & Maximum & Sum & Mean \\
\hline Time to reach hospital (minutes) & 4,198 & 2 & 4,200 & 80,522 & 260 \\
\hline Hospitalized days & 179 & 1 & 180 & 3,877 & 16 \\
\hline Restricted working efficiency for patients (hours) & 289 & 1 & 290 & 1,591 & 7 \\
\hline Time given by caregiver (days) & 644 & 1 & 645 & 6,433 & 23 \\
\hline
\end{tabular}

Table 6: Household direct preventive cost (NPR)

\begin{tabular}{lllll}
\hline Preventive (Adaptation) Cost & Minimum & Maximum & Mean & Standard deviation \\
\hline Amount paid for net & 300 & 70,000 & 8,862 & 8,345 \\
Payment for a mosquito net & 200 & 70,000 & 2,432 & 4,980 \\
Amount paid for pesticide & 20 & 4,000 & 853 & 542 \\
Payment for skin care product & 100 & 2,000 & 467 & 307 \\
Payment for the water treatment device & 300 & 35,000 & 2,977 & 5,949 \\
Payment for the toilet device & 50 & 4,000 & 602 & 555 \\
Payment for program & 0 & 2,500 & 537 & 563 \\
House repair expenditure & 1,000 & 200,000 & 16,871 & 32,827 \\
Payment for Fan & 1,000 & 125,000 & 9,079 & 11,683 \\
Payment for Fridge & 15,000 & 350,000 & 44,000 & 67,447 \\
Price paid for special cloth & 1,000 & 5,000 & 2,617 & 8,465 \\
Payment for reservation tank & 1,000 & 80,000 & 7,916 & 10,527 \\
Expenditure for the water outlet & 1,000 & 20,000 & 4,357 & 4,119 \\
Paid for lightening prevention & 500 & 3,500 & 2,500 & 8,226 \\
\hline
\end{tabular}

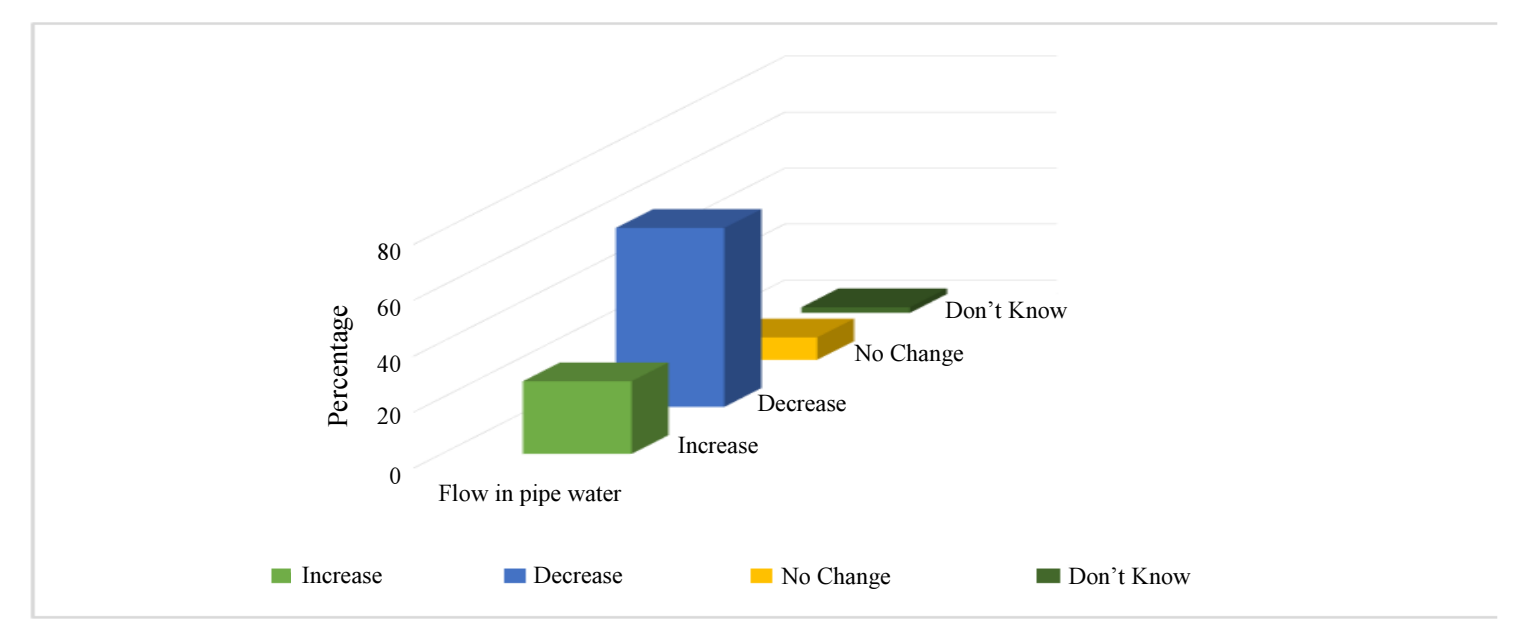

Fig. 6: Water flow in piped water source

Unfortunately, many rivers in the hilly areas and ponds/wells in the Terai region have already dried as well, $80 \%$ of respondents have seen dried river and $76 \%$ of terai residents of the study area have faced dried tube wells. Another catastrophic result is that two-thirds of the total households have experienced decreasing water to dry up in the spout. About $76 \%$ of them have already seen the dried spout which may produce a terrible drinking water scarcity in western Nepal. The flow of piped water, a major water source for drinking purpose mostly in the region, seems in decreasing trend in the study areas as illustrated in Fig. 6. 


\section{Effect on Biodiversity}

A mixed argument of the people is found against biodiversity loss around the community. A highest, $42 \%$ of them were in the favor of the change in available trees compared to 15 years before, $30 \%$ stands against the change and remaining $28 \%$ are unknown about the change in any trees. Sal, Uttis, Khayar, Pipal, Sisau and Bamboo are the trees decreasing over time in Terai region. Similarly, Sal, Simal, Khanaye, Kimbu and Vimal trees are under the category of decreasing surrounding the hilly community. Bail and Ipil-ipil trees are the increasing species, however, Simtara and Koiralo trees are almost disappeared.

Regarding the grass, Athigra, Banso, Dubo and Jaighas are getting declined over time in hilly areas. Almost $31 \%$ of households are feeling a change in grass composition in their field. Because of low grass production in Terai region, most of the people are unknown about the grass species change in the field. Ipil-ipil, Amrisho and Raunna are the increasing species in the hilly areas. Lampate and Khar have already disappeared. Akashbeli and Dante are the newly appeared species in the study areas.

Comparatively, few households (26\%) have responded in the favor of changed water animals. And a highest $44 \%$ of households are unknown about the change in water animals compared to 15 years before. Those who responded for change have argued that fish, frog, crab and snakes are decreasing continuously in the river of hilly areas and crocodiles are not seen in the bank of the river as they appeared some years ago. No single water animals are getting increased, disappeared and newly appeared in the study areas.

Owing to possibly unwitting the value of medicinal plant and non-timber forest, only $20 \%$ of the total households responded to the change in medicinal and non-timber plants in the forest. As per the people in the favor of the change; Tulasi, Chutro, Kaulo, Ghottapre, Tejpatta, Neem, Babari and Timur are the species of plants getting decreased. All these changes showed that biodiversity, one of the potential environmental components, has been changed since 15 years ago in the study areas. Change in species of flora and fauna in the community may change the rate of disease prevalence.

\section{Household Behavior}

Household behavior is directly related to the incidence and prevalence of diseases in a particular community. Around $67 \%$ of total households have responded washing their hands with soap before their meal. Similarly, water only and ash are also actively used for the wash of hands. Almost $93 \%$ of households wash all the cooking devices before and after cooking. More than two third of total households prefer deeply cooked food rather than lightly cooked food.
Interestingly, the highest number (38\%) of households used to eat the stale food again which increase the possibility of disease occurrence in the household. $36 \%$ of them feed the stale food to the domestic animals. $23 \%$ of households dispose of the food in waste collection spot. And only $4 \%$ of them use stale food to make composts, which can be the best practice at household level for the safety of human health.

Collection of solid waste obtained from the kitchen is inside the kitchen of only $8 \%$ of household whereas $92 \%$ collect their waste outside the kitchen. Most of the households (48\%) use to throw the general solid waste to their surrounding of home. Polythene bag seems more popular for those who collect the waste at a place. Open bin and bin with the cap are also used in Terai region rather than hilly region for the collection of wastes. A bitter truth is that houseflies and other insects can come to the kitchen of $78 \%$ of the households from collected waste irrespective of the place of waste collection. Remarkably, $58 \%$ of the households drink untreated water which might bring a different chance of having waterborne diseases. With the view of their preferences, $80 \%$ of households prefer non-boiled water.

\section{Effect on Life Insurance and Health Insurance}

Only $8.8 \%$ of the households have government endorsed life insurance mostly popular in Terai region while not being effective in the hilly region of western Nepal. In Terai, people do not have life insurance but they have insured their vehicles for the security of any unexpected events. Almost $11 \%$ of the households in the Terai region have their vehicles insured.

Health insurance is one of the enlightened issues all over the country at present. About $57 \%$ of respondents have listened about health insurance. An exciting interest towards the health insurance of residents in the hilly region has covered only $13 \%$ of the households in the study area now. The interest on health insurance seemed higher in hilly regions than in terai regions based on their present insured status and possibly the cause of security in the health of their family.

Of those who have not insured, $74 \%$ of households are willing to have insured and only $2 \%$ are unknown about health insurance program of the government. The average willingness to pay for health insurance is NPR 2,784 (Variance: 0.41) ranging from 500 to 10,000 , which is slightly higher than existing government rate (NPR 2500). At the same time, 22\% of total households denied having health insurance. Those who denied are mainly due to unaffordability (64\%) and not seeing any benefit (14\%) from having the health insurance.

\section{Household's Willingness to Pay}

The average household willingness to pay to avoid any kind of risk of health hazards caused by environmental change is elicited as NPR 1,909 (variance: 0.43 ) with the 
range of 500 to 8000 in western Nepal. The average WTP of the household in the Terai region is NPR 1,727 with the range of 500 to 5,000 which is slightly greater than the willingness to pay of household in hilly regions elicited as NPR 2,110.

\section{Discussion}

Being consistent with the recent World Health Statistics reports concluding the major challenges for SDG health-related indicators including 2030 agenda in terms of reducing malnutrition and achieving further progress in the battle against infectious diseases such as tuberculosis, malaria, neglected tropical diseases and hepatitis (WHO, 2017), this study also showed the increasing problems of malnutrition, vector-borne diseases waterborne diseases, heart diseases, population pressures and health system deficiencies (McIver et al., 2015). Evidence from economics based data on climate change, water and sanitation and air quality seem urgent needs to be done to reduce risks to health to recover the present major deficiencies in universal health coverage for basic health services and inadequate preparedness for health emergencies (WHO, 2016; 2017).

This study also found that problems of increasing air pollution leading to increasing infectious diseases, waterborne diseases, cardiorespiratory diseases and others. This result follows WHO-SEA environmental report mentioning climate change and air pollution of the countries Maldives, India and Pakistan (ASCI, 2009; Asian Development Bank, 2008). However, Maldives is comparatively less vulnerable to air pollution and solid waste management but highly affected by limited freshwater resources, heat-related illnesses, limited infectious diseases etc. which are climate sensitive issues. Indian case is too vulnerable regarding air pollution, climate change, water pollution and other environmental degradation. Besides air pollution in Nepal, Pakistan and Bangladesh, climate change is the top challenge on health sectors where mitigation and adaptation strategy with a common program, National Adaptation Program of Action in Nepal was developed in 2010 and is ready for implementation as a national plan and strategy for addressing the health risks of climate change (ASCI, 2009; WHO, 2017).

Extreme weather-related mortality in the United States shows that two third of total deaths are due to excessive natural heat and remaining are due to excessive cold and others (Jiang et al., 2015), but, might be negligible, mortality from the thunderstorm, hot events and heavy rainfall and other climatic induced disasters has slightly appeared in Nepal. Recently it has been predicted that extreme hot weather events may cover $72 \%$ of the national population of Korea by $2090 \mathrm{~s}$ if current trend remains the same (Shim et al., 2017). Unexpected excess rainfall in Europe has made water contaminated with Arsenic and Antimony, subsequently degrading to the human health through food chain (Cann et al., 2013). A modeling aspect between extreme weather events and human vulnerability in Europe predicts that Europe will have two-thirds population vulnerable in terms of the climatic effect on human health by the end of this century (Forzieri et al., 2017). Similarly, heat-related weather events claimed 2,248 deaths in 2015 in India (Hashim and Hashim, 2016) meaning that extreme weather events under climate change are directly or indirectly increasing the disease occurrence in South Asian countries including Nepal.

As other Nepal based study, Nepalese people need in improving preparedness and adaptation strategies such as coping effectively with diseases through improvement of infrastructure and facilities, assessing and educating the vulnerable section of society and enforcing regulations to protect the environment (Shrestha et al., 2017). This study recommends ecological studies to understand the possible consequences of global warming and effective methods to control vectors of Dengue and Yellow fever (Shope, 1991). However, due to ecological and societal change, politics and economic changes; future changes in climate may alter the prevalence and incidence of the diseases and global warming as a dominant parameter is indefensible for the spread of diseases (Reiter, 2008). Therefore, there is an urgent need for cheap, effective control campaigns, as were implemented during the DDT era based on new technologies to address the future climate change.

The average household health inaction cost induced by environmental degradation is not found economically evaluated for the comparison with other. However, economic evaluations of climate mitigation policies could explore the major health co-benefits, covering much of the cost of the initial investment on environmental improvement. Globally, a $1^{\circ} \mathrm{C}$ warming would be a positive $2 \%$ of gross world product, with a standard deviation of $1 \%$ (World Resource Institute, 2003). Under a scenario assuming emissions reductions resulting in stabilization at $750 \mathrm{ppm} \mathrm{CO}_{2}$ equivalent in 2210 , the costs of treating diarrheal diseases, malnutrition and malaria in 2030 were estimated to be $\$ 4$ to $\$ 12$ billion (Ebi, 2008). A Korean study found that the total burden of disease related to climate change in Korea was 6.85 DALY/1000 Korean population in 2008 (Yoon et al., 2014). Another study claims that the combined value of market and nonmarket damage across some sectors: agriculture, crime, coastal storms, energy, human mortality and non-linear labor increases in global mean temperature, costing roughly $1.2 \%$ of gross domestic product per $+1{ }^{\circ} \mathrm{C}$ on average (Hsiang et al., 2017).

Both direct and indirect effect on health could be expected further enhanced with social and environmental 
differences within the country and lack of preparedness of the health system to adapt (Dhital and Koirala, 2016). The Japanese Encephalitis cases were reported in 63 of 77 districts (84\%), expanding in the mountain and hill regions (Pant et al., 2017). In Nepal, vector-borne diseases- Chikungunya malaria, dengue, Japanese Encephalitis; water-borne diseases-bacillary diarrheal disease including cholera; foodborne diseases, malnutrition, cardiorespiratory diseases, psychological stress and health effects and injuries related to extreme weather are major climate-sensitive health risks. Because of the low level of limited scientific facts of climate and health in Nepal, prospective longitudinal study with the inclusion of economic evaluation on climatic effect over health is recommended and seemed an urgent need for the development of climate adaptation policy and health system management accordingly in the country.

Besides, this study also comprises some limitations. First, this study has incorporated the descriptive analysis of the stated objective, with a strong commitment to exploring econometric modeling in the forthcoming issues. Second, this study covers only western heavily disease rampant areas of Nepal. And finally, this study has not covered all the environmental components such as a change in soil, toxic pollutants etc. Regardless, with these pitfalls, this study has concocted current impact of environmental change on human health in terms of healthcare cost. Moreover, this study has first initiated the development of evidence over the economic impact of environmental (climatic and non-climatic) degradation on infectious and non-infectious diseases in terms of health inaction cost and adaptation cost.

\section{Conclusion}

This study has developed a framework about the consequences of environmental degradations in terms of natural disasters and catastrophic payment of increasing diseases outbreak affected Nepalese households due to climate, air and water induced several acute and chronic diseases. Loss of flora and fauna in Nepal poses a great deal of environmental conservation failure. A gigantic cost of households for the prevention and cure against the increasing trend of disease prevalence in the western Nepal suggests an urgent national environmental protection campaign with immediate resolution measures for the control of disease in the affected areas and medication help to the local residents, so that further impoverishment due to catastrophic payment could be avoided. A highly interesting matter of health insurance must be extended to the poor residents. All in all, environment protection seems the potential factor for the healthy human, economically sound household lifestyle and livable prosperous society. Adoption and implementation of findings of this research can provide the necessary tools and infrastructure to pose scientific striving requests and design effective clarifications to the complex issues imposed by effects of environmental change on infectious and non-infectious diseases through the aid of economically valued inputs and outputs. Regarding the policy perspective, this study might be the destiny in the formulation of environmental conservation plan and generation of self-motivation to people at disease prone areas caused by environmental degradation. Current national climate adaptation plan formulation might be more output-oriented from the use of the result of this study.

\section{Funding Information}

This research paper has prepared without any external funding source.

\section{Acknowledgment}

The author acknowledges comments and suggestions for Faculty of Tribhuvan Univesity; Bimala Baral, Co-worker in Research; and University Grants Commission Nepal.

\section{Author's Contributions}

Uttam Paudel: Prepared the manuscript.

Shiva Raj Adhikari and Krishna Prasad Pant: Revised the manuscript and all the authors finalized and approved the manuscript.

\section{Conflict of Interest}

The authors declare that there is no any conflict of interest.

\section{References}

Acevedo-Whitehouse, K. and A.L.J. Duffus, 2009. Effects of environmental change on wildlife health. Philosophical Transactions Royal Society B: Biological Sci., 364: 3429-3438.

DOI: $10.1098 /$ rstb.2009.0128

Alam, P. and K. Ahmade, 2013. Impact of solid waste on health and the environment. Int. J. Sustainable Development Green Economics, 2: 165-168.

DOI: 10.1016/j.wasman.2005.01.020

ASCI, 2009. Analysis of Existing Environmental Instruments in India. UNDP, New Dehli.

Asian Development Bank, 2008. Islamic Republic of Pakistan: Country Environment Analysis. Production.

Bonjour, S., H. Adair-Rohani, J. Wolf, N.G. Bruce and S. Mehta et al., 2013. Solid fuel use for household cooking: Country and regional estimates for 1980 - 2010. Environment Health Perspectives, 784: 784-790. 
Cann, K.F., D.R. Thomas, R.L. Salmon, A.P. Wyn-Jones and D. Kay, 2013. Extreme water-related weather events and waterborne disease. Epidemiology Infec., 141: 671-686. DOI: 10.1017/S0950268812001653

Chan, N.Y., K.L. Ebi, F. Smith, T.F. Wilson and A.E. Smith, 1999. An integrated assessment framework for climate change and infectious diseases. Environ Health Perspect, 107: 329-337.

DOI: 10.1289/ehp.99107329

Dhital, S. and M. Koirala, 2016. Climate change and its impacts on human health in Nepal. J. Health Education Res. Development, 4: 4-7. DOI: $10.4172 / 2380-5439.1000174$

Ebi, K.L., 2008. Adaptation costs for climate changerelated cases of diarrhoeal disease, malnutrition and malaria in 2030. Globalization Health, 4: 1-9.

DOI: $10.1186 / 1744-8603-4-9$

Forzieri, G., A. Cescatti, F.B. Silva and L. Feyen, 2017. Increasing risk over time of weather-related hazards to the European population: A data-driven prognostic study. Lancet Planetary Health, 1: e200-e208. DOI: $10.1016 / \mathrm{S} 2542-5196(17) 30082-7$

Hashim, J.H. and Z. Hashim, 2016. Climate change, extreme weather events and human health implications in the Asia Pacific Region. Asia Pacific J. Public Health, 28: 8S-14S. DOI: $10.1177 / 1010539515599030$

Hsiang, S., M. Delgado, S. Mohan, D.J. Rasmussen and R. Muir-Wood et al., 2017. Estimating economic damage from climate change in the United States. Science, 356: 1362-1369.

DOI: $10.1126 /$ science.aal4369

Jiang, C., K.S. Shaw, C.R. Upperman, D. Blythe and C. Mitchell et al., 2015. Climate change, extreme events and increased risk of salmonellosis in Maryland, USA: Evidence for coastal vulnerability. Environ. Int., 83: 58-62.

DOI: $10.1016 /$ j.envint 2015.06 .006

Liang, L. and P. Gong, 2017. Climate change and human infectious diseases: A synthesis of research findings from global and spatio-temporal perspectives. Environ. Int., 103: 99-108.

DOI: $10.1016 /$ j.envint.2017.03.011

McIver, L., R. Kim, A. Woodward, S. Hales and J. Spickett et al., 2015. Health impacts of climate change in pacific island countries: A regional assessment of vulnerabilities and adaptation priorities. Environ. Health Perspectives, 124: 1-31. DOI: $10.1289 / \mathrm{ehp} .1509756$

MOHP, 2011. Annual Report of Health. Ministry of Health and Population, Kathmandu, Nepal

Pant, D.K., T. Tenzin, R. Chand, B. Kumar Sharma and P.R. Bist, 2017. Spatio-temporal epidemiology of Japanese encephalitis in Nepal, 2007-2015. PLoS ONE, 12: 2007-2015.

DOI: 10.1371/journal.pone.0180591
Paudel, U. and K.P. Pant, 2018. Environmental determinants of disease prevalence in rural Western Nepal. J. Environm. Protection, 9: 1221-1236. DOI: $10.4236 /$ jep.2018.912077

Paudel, U., 2018a. A review of effects of environmental change on human health. Am. J. Environ. Sci., 14: 95.109. DOI: $10.3844 /$ ajessp. 2018

Paudel, U., 2018b. Environment disease relationship and its impact on household economy. Biomedical J. Scientific Technical Res., 5: 1-6. DOI: 10.26717/BJSTR.2018.10.001927

Prüss-Ustün, A., J. Wolf, C. Corvalán and R. Bos, 2016. Preventing disease through healthy environments: A global assessment of the burden of disease from environmental risks. World Health Organization, 20 Avenue Appia, 1211 Geneva 27, Switzerland.

Reiter, P., 2008. Global warming and malaria: Knowing the horse before hitching the cart. Malaria J., 7: 1-9. DOI: $10.1186 / 1475-2875-7-S 1-S 3$

Sattenspiel, L., 2000. Tropical environments, human activities and the transmission of infectious diseases. Am. J. Physical Anthropology, 31: 3-31.

DOI: $\quad 10.1002 / 1096-8644(2000) 43: 31+<3:: A I D-$ AJPA2>3.0.CO;2-Z

Shim, C., J. Seo, J. Han, J. Ha and T.H. Ro et al., 2017. Projection of future hot weather events and potential population exposure to this in South Korea. Climate Res., 72: 29-38. DOI: 10.3354/cr01446

Shope, R., 1991. Global climate change and infectious diseases. Environm. Health Perspectives, 96: 171-174. DOI: 10.1289/ehp.9196171

Shrestha, S.L., I.L. Shrestha, N. Shrestha and R.D. Joshi, 2017. Statistical modeling of health effects on climate-sensitive variables and assessment of environmental burden of diseases attributable to climate change in Nepal. Environm. Modeling Assessment, 22: 459-472. DOI: $10.1007 / \mathrm{s} 10666-017-9547-5$

Tjaden, N.B., J.E. Suk, D. Fischer, S.M. Thomas and C. Beierkuhnlein and J.C. Semenza, 2017. Modelling the effects of global climate change on Chikungunya transmission in the 21 st century. Scientific Reports, 7: 3813. DOI: 10.1038/s41598-017-03566-3

Tol, R.S.J., 2009. The economic effects of climate change. J. Economic Perspectives, 23: 29-51. DOI: $10.1257 /$ jep.23.2.29

WHO, 2016. World health statistics- monitoring health for the SDGs. World Health Organization.

WHO, 2017. World health statistics 2017: Monitoring health for the SDGs. World Health Organization.

World Resources Institute, 2003. World Resources 20022004: Decisions for the Earth: Balance, Voice and Power. 
Yoon, S.J., I.H. Oh, H.Y. Seo and E.J. Kim, 2014. Measuring the burden of disease due to climate change and developing a forecast model in South Korea. Public Health, 128: 725-733. DOI: $10.1016 /$ j.puhe.2014.06.008

Young, H.S., C.L. Wood, A.M. Kilpatrick, K.D. Lafferty and C.L. Nunn et al., 2017. Conservation, biodiversity and infectious disease: Scientific evidence and policy implications. Philosophical Trans. Royal Society B: Biological Sci., 372: 20160124. DOI: $10.1098 /$ rstb.2016.0124
Zuckerman, J.N., 2012. Infectious diseases: A geographic guide. Travel Medicine Infectious Disease. DOI: $10.1016 /$ j.tmaid.2011.12.002 